\title{
Interpersonal Trust between Marketing and R\&D during New Product Development Projects
}

\author{
Graham R. Massey - University of Technology, Sydney * \\ Elias Kyriazis - University of Wollongong
}

Graham R. Massey

School of Marketing

University of Technology, Sydney

PO Box 123, Broadway NSW 2007

AUSTRALIA

Phone: +612-9514-3480

Fax: +612-9514-3535

Email: graham.massey@uts.edu.au
Elias Kyriazis

School of Management and Marketing University of Wollongong 2522 NSW AUSTRALIA

Phone: +61-0242-214-871

Fax: +61-0242-214-154

Email: elias_kyriazis@uow.edu.au

* Please direct all correspondence to the $1^{\text {st }}$ author 


\title{
Interpersonal Trust between Marketing and R\&D during New Product Development Projects
}

\begin{abstract}
Purpose - The primary objective of this research is to test a model examining interpersonal trust between marketing managers and R\&D managers during new product development projects. In this study we conceptualise interpersonal trust as a bidimensional construct with cognitive and affective components. Our integrative structural model specifies Weber's (1924) structural/bureaucratic dimensions formalisation and centralisation to predict three communication dimensions, communication frequency, quality, and bidirectionality. In turn these communication dimensions are used to predict cognition-based trust, and affect-based trust. In addition, we model the direct effects of our three communication dimensions on our dependent variable - perceived relationship effectiveness.
\end{abstract}

Design/methodology/approach - Our hypothesised model consists of sixteen hypotheses, seven of which relate to our two focal interpersonal trust constructs. Our measures were tested and our structural model estimated by using PLS. Data was provided by $184 \mathrm{R} \& \mathrm{D}$ managers in Australia, reporting on their working relationship with a counterpart marketing manager during a recent product development project.

Findings - Our hypothesized model has high explanatory power and we found that both trust dimensions strongly influenced the effectiveness of marketing/R\&D relationships during new product development, with cognition-based trust having the strongest impact. Our results also reveal which forms of communication help to build interpersonal trust. The most powerful effect was from communication quality to cognition-based trust. The next strongest effects were from bidirectional communication, which was a strong predictor of affect-based trust, and a somewhat weaker predictor of cognition-based trust. Interestingly, the direct effects of our three communication behaviours on relationship effectiveness were modest, suggesting that their relationship building effects are largely indirect. Last, we reveal that bureaucratic means of control on product development projects have mixed effects. As expected, centralisation reduces cross-functional communication. In contrast, formalisation has a positive effect during product development, as it stimulates both the frequency and bidirectionality of communication between marketing managers and $R \& D$ managers on these projects.

Originality/value - This is the first study to treat interpersonal trust as the focal construct in marketing/R\&D relationships during new product development. Moreover, it is the only study of marketing/R\&D relationships to conceptualise, measure, and model two underlying dimensions of interpersonal trust (cognitionbased trust, and affect-based trust). Our study also integrates aspects of Weber's (1924) theory of bureaucracy, with interaction theory, and demonstrates the strong links between these theoretical frameworks.

Keywords Interpersonal trust; cross-functional relationships, marketing/R\&D relationships, new product development

Paper type Research paper 


\section{Introduction}

Since Ruekert and Walker's (1987) landmark study, marketing's cross-functional relationships have become an important focus of academic research. Evidence of this can be seen in the large and growing literature examining marketing relationships, and marketing's integration with other departments (e.g., Dawes and Massey, 2005, 2006; Fisher et al., 1997; Workman et al., 1998). The topic is theoretically and managerially important because increasingly, today's flatter organisations require personnel to secure cooperation from individuals in other departments over whom they have no hierarchical control (Williams, 2001). Similarly, Webster (1997) suggests that an ability to manage cross-functional relationships will be an important skill for marketing managers in the future.

Cross-functional relationships are vital during new product development (NPD) because NPD involves converting abstract ideas into tangible products. NPD requires interdependent specialists to provide or exchange resources such as information, expertise, and money (Lawrence and Lorsch, 1967; Olson et al., 1995), and crossfunctional relationships facilitate these exchanges.

The focus of this study is interpersonal trust in cross-functional relationships between marketing and R\&D during NPD. We focus on this particular managerial dyad because it is well established that these two managers are among the most important decision makers during NPD projects (e.g., Wind, 1981, 1982). The extent to which these two managers trust each other is important because there is strong evidence that the more effectively marketing and R\&D work together during NPD, the greater the likelihood of developing a successful new product (Maltz et al., 2001; Shaw and Shaw, 1998; Souder, 1981, 1988).

Improving success rates of NPD projects is important for firms because new products have major strategic implications, e.g., for portfolio management, medium to long-term cash flows, and even the long-term survival of the firm (Cooper, 1996; Crawford and DiBenedetto, 2003). Empirical evidence suggests however, that marketing/R\&D relationships during NPD are often problematic (Shaw and Shaw, 1998), therefore improving these relationships is a critical managerial challenge.

In this article we focus on the role of interpersonal trust in improving marketing manager/R\&D manager relationships during NPD. A key argument we advance here is that the very nature of NPD projects (e.g., group problem solving under conditions of high uncertainty; non-programmable problems) pose particular coordination challenges. We believe that these difficulties can be mitigated when interpersonal trust exists between NPD team members. We argue this because complex tasks create behavioural interdependence (Pfeffer and Salancik, 1978), and heighten the need for coordinating activities (Jones et al., 1997), and trust is known to act as an informal coordination mechanism (Jones and George, 1998). As Rousseau et al. (1998) note, in increasingly fluid and decentralised work settings such as NPD projects, trust can help workers to self-organise, and lead to trust-related behaviours such as cooperation.

Importantly, because of the complexity of NPD projects, the direct effectiveness of formal/bureaucratic means of coordination is likely to be low. In arguing this we do not suggest that formal mechanisms will be ineffective during NPD, rather, that they have a specific, but indirect role to play in fostering effective relationships.

Our paper is structured as follows. First we outline the theoretical foundations of this research. We then present our conceptual framework, define the key constructs, and justify their inclusion in our model. Next we present our structural model and develop our hypotheses. We then describe our research methods, and report the results 
of our empirical tests. We conclude by discussing the implications of our research, its limitations, and possible topics for future research.

\section{Theoretical foundations}

We draw on two theoretical foundations to develop our model, first Weber's (1924) theory of bureaucracy, from which we draw our two structural variables formalisation and centralisation. We include these because both the management and marketing literature identify them as important aspects of internal coordination (e.g., Ayers et al., 1997; Rajagopalan et al., 1993), and they are therefore both likely to influence coordination and effectiveness in marketing/R\&D relationships.

We also draw on the interaction approach, which is used in many important studies of marketing's relationships (e.g., Moenaert et al., 1994; Ruekert and Walker, 1987). The interaction approach focuses on how factors such as communication and trust predict satisfaction, performance, and relationship continuity in various contexts, e.g., buyer-seller and channel relationships (cf. Anderson and Narus, 1990; Morgan and Hunt, 1994), and cross-functional relationships (e.g., Ruekert and Walker, 1987).

Our choice of these theoretical frameworks allows us to examine various dimensions of marketing/R\&D relationships (e.g., interpersonal trust; communication behaviours), and levels of analysis (e.g., structural versus individual-level). Our use of Weber (1924) allows us to investigate how formalisation and centralisation affect marketing/R\&D relationships. However because these structural/bureaucratic variables lack action-level analysis, i.e., at the level of the human actors (Pennings, 1992), we also examine a number of communication variables drawn from the interaction approach. These include communication frequency, bidirectionality, and quality, and we include these because the current state of any relationship is the result of an ongoing series of interactions (e.g., Young and Wilkinson, 1997).

Importantly, we examine two dimensions of interpersonal trust - cognitionbased, and affect-based trust, because of the salience of trust in working relationships (e.g., Williams, 2001), and because of an emerging consensus that interpersonal trust consists of two underlying dimensions, one cognitive, the other affective (e.g., McAllister, 1995).

In this research we make five contributions. First, while earlier studies examine trust as an outcome of interdepartmental interactions (e.g., Jassawalla and Sashittal, 1998), interpersonal trust has not previously been used as the focal explanatory variable in marketing/R\&D relationships. Second, ours is the first study to examine two forms of trust in NPD projects, and demonstrate their importance. Third, we reveal the differential effects of three communication dimensions - communication frequency, bidirectionality, and quality, in building interpersonal trust and promoting effective relationships during NPD projects. Fourth, we believe our model and findings are generalisable to other marketing relationships, and other situations in which there is cross-functional group decision-making (e.g., in organisational buying centres). Last, by integrating two separate but complementary theories, Weber's (1924) theory of bureaucracy, and the interaction approach, we demonstrate the strong links between these two theoretical frameworks.

\section{Conceptual framework}

Our hypothesised model includes three sets of variables - structural, interaction, and trust, plus our outcome variable, perceived relationship effectiveness. Weber's (1924) bureaucratic dimensions are relevant because this theory suggests that different work situations require different combinations of these variables. Routine tasks such as 
normal production runs for example, require only "mechanistic" structures, i.e., high formalisation and centralisation. In contrast, in situations of high task uncertainty, or where creativity and innovation are required (e.g., NPD projects), more "organic", less formalised and centralised structures are appropriate (Burns and Stalker, 1961; Olsen et al., 1995). Excessive bureaucracy during NPD may be dysfunctional, because the resulting ossification of behaviour can lead to the rejection of innovative ideas (Mintzberg, 1979). However, it is worth noting that some structure is likely to be necessary during NPD to help coordinate activities and information flows. Our model therefore specifies formalisation and centralisation to influence crossfunctional communication during NPD.

Further, both theory and empirical evidence suggest that communication within relationships influences trust development (cf. McAllister, 1995), we therefore link communication to trust in our model. Similarly, communication is believed to directly influence relationship effectiveness (e.g., Ruekert and Walker, 1987), and we therefore link communication directly to our dependent variable, perceived relationship effectiveness. Last, given the importance of trust to the effectiveness of working relationships, we also link our two trust dimensions to our dependent variable. Our hypothesised model is presented below in Figure 1.

\section{[Take in Figure 1]}

\section{Dependent variable: perceived relationship effectiveness}

Our dependent variable perceived relationship effectiveness is drawn from Van de Ven (1976), and relates to whether the R\&D manager perceives their relationship with the marketing manager to be worthwhile, equitable, productive and satisfying. Consistent with Ruekert and Walker (1987) we operationalise this construct at the interpersonal rather than the interdepartmental level. We feel justified using a subjective outcome measure because other studies have done so (e.g., Anderson and Narus, 1990; Smith and Barclay, 1997), and because there is good evidence that the effectiveness of cross-functional relationships is strongly associated with successful NPD outcomes (e.g., Souder, 1981, 1988).

\section{Explanatory variables}

\section{Structural/bureaucratic dimensions}

NPD projects require specialists from different departments with distinct skills, resources, and capabilities, to work together effectively. A key managerial role therefore, is to take an active part in encouraging integration, and directing marketing and R\&D towards the common goals of NPD teams, by implementing appropriate structures (Ayers et al., 1997). Formalisation and centralisation are two means by which this coordination is achieved, and various studies have found that they affect cross-functional relationships on NPD projects (e.g., Olson et al., 1995; Song et al., 1996).

Formalisation is defined as the emphasis placed on following rules and procedures when performing one's job (Pugh et al., 1968). Its purpose is to coordinate the firm's activities by reducing variability in behaviour, and ultimately to predict and control it (Björk, 1975; Mintzberg, 1979). Formalisation reduces confusion because staff know what they are expected to do, therefore during NPD, formalisation can help coordinate effort, and facilitate productive exchanges (Thompson, 1967). 
Centralisation is the extent to which decisions are made at higher levels in a firm's hierarchy (Aiken and Hage, 1968). McCann and Galbraith (1981) argue that a key issue facing top management is to trade-off control against greater adaptability from decentralisation. On NPD projects, management must therefore balance the need for formal mechanisms, without creating a burden from procedural overload (Moenaert et al., 1994). Excessive centralisation can reduce communication and resource sharing between functional specialists (Olson et al., 1995), and we believe it is therefore important to examine the role of centralisation during NPD projects.

\section{Communication dimensions}

Moenaert and Souder (1990a) view the NPD process as primarily informational, and consistent with this, in their comprehensive review of the marketing/R\&D literature, Griffin and Hauser (1996) cite 19 studies supporting the view that information transfer is an antecedent to effective marketing/R\&D relationships. Given this, it is not surprising that many formal NPD systems (e.g., Stage Gate; Concurrent Engineering; Quality Function Deployment) emphasise the importance of crossfunctional communication.

Several communication dimensions are known to affect working relationships, and we examine three of these - communication frequency, bidirectionality, and quality. We include communication frequency because it is a key variable in many types of relationships, including cross-functional relationships (e.g., Ruekert and Walker, 1987). Communication frequency is defined as the intensity of information flow between managers via meetings, reports, and telephone conversations (Van de Ven and Ferry, 1980).

Bidirectional communication is included because recent studies have established its importance in cross-functional relationships (e.g., Dawes and Massey, 2005; Fisher et al., 1997). Moreover, Wheelwright and Clark (1992) note that bidirectional communication is especially important during NPD because it facilitates problem solving between marketing and $\mathrm{R} \& \mathrm{D}$. We define bidirectionality as the extent to which communication between managers is a two-way process (Fisher et al., 1997).

Last, we include communication quality because various studies (e.g., Gupta et al., 1986; Gupta and Wilemon, 1988) have found that the quality of communication flowing from marketing to R\&D during NPD, influences the perceived competence of marketing managers. Communication quality may therefore influence the effectiveness of marketing/R\&D relationships during NPD projects. Consistent with Moenaert et al. (1992) communication quality is defined as how credible, understandable, relevant, and useful the information provided by the marketing manager was for the R\&D manager's task completion.

\section{Interpersonal trust}

The importance of trust in behavioural research is reflected in the range of disciplines which examine this construct, e.g., economics, psychology, management, and marketing. Trust between interdependent actors helps coordinate actions, and improve effectiveness within, and between organisations (Pennings and Woiceshyn, 1987; Seabright et al., 1992). The social exchange literature suggests that trusting behaviours signal interest in, and commitment to relationships (Blau, 1964), while the marketing channels literature identifies trust as an important contributor to effective buyer-seller relationships (e.g., Anderson and Weitz, 1989). Similarly, in the relationship marketing literature, Morgan and Hunt (1994) identify trust as a key variable mediating effective relational exchange. 
Trust is important in cross-functional relationships because managers are boundary spanners who need to develop horizontal ties within the organization (Gabarro, 1990; McAllister, 1995). Overall firm performance can be improved where there is interpersonal trust between managers, because trust can improve crossfunctional cooperation, coordination, and organizational decision-making. Trust also facilitates informal cooperation and coordinated social interaction, and reduces the need to monitor others' behaviour, formalise procedures, or create specific contracts (Williams, 2001).

Importantly, McAllister (1995) found that peer managers who trust each other are more sensitive to each other's personal and work-related needs. In particular, they are less likely to engage in "control-based monitoring", i.e., trying to manage the inherent uncertainty when they cannot count on the reliability of the other manager. Interpersonal trust can also increase "organizational citizenship behavior”, e.g., providing assistance to others that is outside one's work role, not directly rewarded, and which helps organizational functioning. Interpersonal trust also increases "needbased monitoring”, i.e., a sensitivity to and keeping track of colleagues' needs (Clark et al., 1989). Trust can also increase "interpersonal citizenship behavior", i.e., increased assistance, a desire to help peers meet personal objectives, and the tangible expression of care and concern (McAllister 1995).

Conversely, in low trust relationships managers may behave defensively to protect themselves against the effects of unreliable peers. This can involve requesting assistance well before it is actually required, drawing on multiple, redundant sources of assistance, "working around" and avoiding others, and making requests more formally than they would do ordinarily (Ashforth and Lee, 1990; McAllister, 1995). Interpersonal trust can therefore be invaluable to organisations in general, but especially to firms using cross-functional teams or other collaborative structures to coordinate work.

Interpersonal trust has been conceptualised in various ways in the literature, for example, as credibility, in which the trusted person fulfils oral or written statements or promises (e.g., Ganesan, 1994). Another perspective is that trust involves benevolence - a general concern for other people, which transcends the personal profit motive (e.g., Rempel et al., 1985). The perspective which we adopt in this paper is that trust is composed of both of these underlying dimensions, one of which is cognition-based, and the other affective in nature (cf. McAllister, 1995). Cognition-based trust arises from previous occasions in which another person has been competent, reliable, and dependable on work related issues. In contrast, affect-based trust is an emotional form of trust, in which one party exhibits genuine care and concern for the welfare of another person.

Importantly, recent empirical research has revealed that these two forms of trust are distinct (e.g., Ganesan and Hess, 1997), and have differing effects on working relationships (e.g., McAllister, 1995). We therefore examine these two underlying dimensions of interpersonal trust to better understand their roles in working relationships between marketing and R\&D during NPD.

\section{Hypotheses development}

\section{Effects of interpersonal trust}

Trust is known to be important in many contexts, e.g., in selling partner relationships (Smith and Barclay, 1997), and between buyers and sellers (Morgan and Hunt, 1994). 
The effects of cognition- and affect-based trust on cross-functional relationships however, are not well understood, though managers who trust each other are likely to assess each other's performance more favourably (McAllister, 1995).

\section{Cognition-based trust}

Because cognition-based trust concerns an individual's beliefs about peer reliability, competence, and dependability (McAllister, 1995), it should be associated positively with relationship effectiveness. Shaw and Shaw (1998) found that when marketing managers lacked credibility, marketing/engineering relationships tend to be poor. Similarly, Gupta and Wilemon's (1990) study of high-technology firms found that $27 \%$ of the R\&D managers surveyed believed that marketing managers did not know enough about marketing to be effective. We therefore argue that R\&D managers with high cognition-based trust in a marketing manager will perceive their relationship to be effective, and hypothesise:

$\mathbf{H}_{\mathbf{1 a}}$ : As cognition-based trust between the R\&D manager and the marketing manager increases, perceived relationship effectiveness will increase.

Both theory (e.g., Lewis and Weigert, 1987), and empirical evidence (e.g., McAllister, 1995) suggest that affect-based trust develops from an existing cognitive base. Once a peer manager is perceived to be competent, reliable, and dependable, affect-based trust is more likely to emerge (McAllister, 1995). In justifying this hypothesis we look to game theory for insights. Game theory predicts that where one party acts in a trusting manner there is a tendency for people to reciprocate this behaviour (Boyle and Bonacich, 1970; Solomon, 1960). This initial display of cooperation is seen as evidence of trustworthiness, and allows the relationship to continue to a point where initial liking (i.e., affect) between parties may occur (Dasgupta, 1988).

Similarly, several trust theorists (e.g., Jones and George, 1998; Lewis and Weigert, 1985; Rousseau et al., 1998; Sheppard and Shermann, 1998) argue that evidence of reliability and dependability from previous interactions with the trustor give rise to positive expectations about the trustee's intentions. Trust develops as the cognitive level of experience is reached when social actors no longer need or want further evidence, or rational reasons for their confidence in the objects of trust. Emotion then enters into the relationship because frequent, longer term interaction leads to the formation of attachments based upon reciprocated interpersonal care and concern (Lewis and Weigert, 1985). This emotional response, which is rich in caring and benevolence is equivalent to McAllister's (1995) affect based trust. Accordingly we hypothesise:

$\mathbf{H}_{\mathbf{1 b}}$ : As cognition-based trust between the R\&D manager and the marketing manager increases, affect-based trust will increase.

\section{Affect-based trust}

Affect-based trust involves reciprocated interpersonal care and concern for another person (Pennings and Woiceshyn, 1987; Rempel et al., 1985), subjective feelings of security against being exploited, and the comfort and assurance that one's interests are being served by another party (Mittal, 1996). Consistent with this, managers reporting high affect-based trust look for more opportunities to meet peers' work-related needs, 
and engage in more productive interventions (McAllister, 1995). Therefore, an R\&D manager with high affect-based trust in a marketing manager will be more likely to report that their relationship is effective. Accordingly we hypothesise:

$\mathbf{H}_{1 \mathbf{c}}$ : As affect-based trust between the R\&D manager and the marketing manager increases, perceived relationship effectiveness will increase.

Effects of managerial communication behaviours

Studies of various relationships, whether buyer-seller (e.g., Anderson and Narus, 1990; Doney and Cannon, 1997), or cross-functional (e.g., Song et al., 2000; Souder, 1988) suggest that they are built in part, through effective communication. The nature and pattern of cross-functional communication is a key aspect of cross-functional coordination (e.g., Fisher et al., 1997; Ruekert and Walker, 1987), particularly during NPD (cf. Griffin and Hauser, 1996; Souder and Moenaert, 1992). Wheelwright and Clark (1992) for example note that a key role of senior management is to communicate ideal patterns of involvement, interaction and collaboration during NPD.

\section{Communication frequency}

\section{Bidirectional communication}

When peer managers communicate frequently, that communication is likely to be reciprocated, creating a bidirectional communication flow. This is because norms of reciprocity are deeply ingrained in most social systems (Gouldner, 1960). Consistent with this, Wheelwright and Clark (1992) argue that frequent communication during NPD should therefore lead to higher "reciprocal" (i.e., bidirectional) communication. Also, frequent communication helps increase one's understanding of a peer's operational domain and information requirements (Souder, 1987). More frequent communication should therefore prompt greater bidirectional communication, to satisfy that manager's information needs. We therefore hypothesise:

$\mathbf{H}_{2 \mathbf{a}}$ : Greater communication frequency between the R\&D manager and the marketing manager will lead to greater bidirectional communication.

\section{Cognition-based trust}

Social exchange theory predicts that frequent interaction (of which communication is a key component) allows people to assess the competence and reliability of others (Blau, 1964). As noted previously, competence and reliability are important facets of cognition-based trust. Because communication frequency provides necessary information to assess a peer manager's role competence, communication frequency should be positively associated with cognition-based trust. Support for this is provided by Becerra and Gupta (2003) who found a strong positive correlation between frequent communication and perceived trustworthiness of peer managers. We therefore hypothesise:

$\mathbf{H}_{\mathbf{2 b}}$ : Greater communication frequency between the R\&D manager and the marketing manager will lead to greater cognition-based trust.

Perceived relationship effectiveness 
A key tenet of the interaction approach is that effective relationships are built on a foundation of frequent communication. This is because frequent communication is believed to promote mutual understanding, harmonious relationships, and improve joint decision-making (cf. Griffin and Hauser, 1996). Consistent with this, in their study of communication between marketing and engineering during NPD, Fisher et al. (1997) found a positive relationship between communication frequency and perceived relationship effectiveness. Also, Song et al. (1996) found that R\&D employees identified a lack of communication as a major barrier to them building effective relationships with marketing. Infrequent communication might therefore indicate that the relationship is ineffective, and we therefore hypothesise:

$\mathbf{H}_{\mathbf{2}}$ : Greater communication frequency between the R\&D manager and the marketing manager will lead to greater perceived relationship effectiveness

\section{Effects of bidirectional communication}

Bidirectional communication involves the exchange of information to achieve mutual goals (Mohr et al., 1996) and should therefore be important during NPD projects. Souder (1987) argues for example, that the sharing of project data and facts helps build creative synergy, by allowing parties to agree on the division of labour, define their roles, and determine which tasks each is best able to perform.

\section{Quality of communication}

No previous studies have examined the relationship between bidirectional communication and communication quality, although Dougherty (1992) suggests that interdepartmental feedback and elaboration can improve managers' perceptions of others' inputs. Also, Fisher et al. (1997) found that bidirectional communication between marketing and engineering managers during NPD correlated strongly with information use. Managers with a high propensity to use information provided are therefore likely to perceive that information to be of high quality. Bidirectional communication should therefore be positively associated with information quality, and we hypothesise:

$\mathbf{H}_{3 \mathbf{a}}$ : Greater bidirectional communication between the R\&D manager and the marketing manager will lead to greater quality of communication.

\section{Cognition-based trust}

As with our previous hypothesis, no prior research has examined the link between bidirectional communication and cognition-based trust. However, drawing on relevant theory, and recent studies examining the effects of bidirectional communication in cross-functional relationships (e.g., Dawes and Massey, 2005; Fisher et al., 1997) we argue that bidirectional communication is likely to be an important factor during NPD. Bidirectional communication can help overcome one of the greatest barriers to effective working relationships between marketing and R\&D, i.e., the "credibility" problem (Gupta and Wilemon, 1988; Shaw and Shaw, 1998). Moenaert and Souder (1990b) found that R\&D managers struggle with jargon-filled marketing data, and one key mechanism for improving their understanding is via what Moenaert and Souder (1990b) refer to as "interactive communication" which we interpret to be equivalent to "bidirectional communication." We therefore argue that bidirectional communication and cognition-based trust will be positively related. Bidirectionality is a reciprocal form of communication, allowing managers to demonstrate the work- 
related reliability which is the basis of cognition-based trust. In addition, decisionmaking during complex tasks such as NPD requires effective information exchange between managers, therefore high bidirectional communication suggests that those managers have work-related confidence in each other (i.e., cognition-based trust). Thus, we predict:

$\mathbf{H}_{3 \mathbf{b}}$ : Greater bidirectional communication between the R\&D manager and the marketing manager will lead to greater cognition-based trust.

\section{Affect-based trust}

In contrast to communication frequency, which may consist mostly of impersonal communication such as e-mails or memoranda, bidirectional communication is often more informal and personal (Huber and Daft, 1987). Social exchange theory (e.g., Blau, 1964) suggests that such informal or reciprocal communication is an effective way of assessing the intentions of a peer manager. Because interpersonal cues are generally harder to misconstrue in face-to-face interactions (Good, 1988) bidirectional communication may allow social aspects of relationships to emerge. Therefore, where bidirectional communication is high, peer managers are more likely to hold favourable beliefs about the other person, and have the other's interests at heart. Thus, we predict:

$\mathbf{H}_{3 \mathbf{c}}$ : Greater bidirectional communication between the R\&D manager and the marketing manager will lead to greater affect-based trust

Perceived relationship effectiveness.

Feedback is important because it provides communicators with opportunities to clarify their messages and reduce misunderstandings (Fisher, 1978), thereby improving cross-functional relations. Bidirectionality should therefore be positively associated with relationship effectiveness. Empirical support for this proposition was provided by Fisher et al's (1997) study of factors affecting communication between marketing and engineering. In this study they found a positive link between bidirectional communication and perceived relationship effectiveness, and we therefore predict:

$\mathbf{H}_{\mathbf{3 d}}$ : Greater bidirectional communication between the R\&D manager and the marketing manager will lead to higher perceived relationship effectiveness.

\section{Quality of communication}

Because R\&D require information from marketing to achieve their NPD goals, the higher the perceived quality of this information, the greater will be R\&D's work related confidence in the marketing manager. Gupta and Wilemon (1988) found that when R\&D perceived marketing's information to be credible, understandable, relevant, and useful for task completion (i.e., high quality), the marketing manager was perceived to be more trustworthy, competent, and knowledgeable. Similarly, Jassawalla and Sashittal (1998) found that in firms reporting high levels of functional integration, marketing managers who provided high quality information were viewed as professional and competent. Also, Moenaert and Souder (1990b) found that when $\mathrm{R} \& \mathrm{D}$ managers believe the marketing manager is not competent, they screen out information from that manager. As cognition-based trust concerns work-related 
competence and professionalism, both of which can be demonstrated via quality communication, we hypothesise:

$\mathbf{H}_{\mathbf{4 a}}$ : Greater quality of communication between the R\&D manager and the marketing manager will lead to greater cognition-based trust.

\section{Perceived relationship effectiveness}

A number of scholars view marketing's primary role during product development as acquiring and providing $\mathrm{R} \& \mathrm{D}$ with relevant information regarding user needs, competition, and resources (e.g., Gupta et al., 1985; Moenaert and Souder, 1990a). Because $R \& D$ depends on this information to achieve its goals, the quality of marketing's communication is likely to affect their NPD performance. Therefore where marketing provide $R \& D$ with high quality information, $R \& D$ managers can better achieve individual and joint goals (Gupta and Wilemon, 1988), and will perceive their relationship with marketing to be effective. We therefore hypothesise:

$\mathbf{H}_{4 \mathbf{b}}$ : Greater quality of communication between the R\&D manager and the marketing manager will lead to higher perceived relationship effectiveness.

\section{Effects of the structural dimensions}

Formalisation and centralisation are important factors influencing cross-functional relationships during product development projects (Ayers et al., 1997; Song et al., 1996) and one of their main impacts is on communication flows between marketing and R\&D (Moenaert et al., 1994).

\section{Effects of formalisation}

Formalisation during NPD projects establishes managers' role expectations and expected information flows (Moenaert and Souder, 1990a). Rules and standard operating procedures often specify high levels of cross-functional communication. Consistent with this, Ruekert and Walker (1987) found that higher formalisation was associated with increased communication between marketing and R\&D, manufacturing, and accounting. Similarly, Moenaert and Souder (1990b) found that formalisation increased both formal and informal communication between marketing and R\&D personnel during NPD. We therefore hypothesise:

\section{$\mathbf{H}_{5 a}$ : Greater project formalisation will lead to greater communication frequency between the $R \& D$ manager and the marketing manager}

In extending their previous research into cross-functional communication, Moenaert et al. (1994) found that formalisation was positively associated with communication flows from marketing to $R \& D$, and also from $R \& D$ to marketing, i.e., bidirectional communication. Similarly, Song et al. (1996) found that formalisation had a positive effect on information exchange between marketing and R\&D in the planning phase of NPD projects. Using these two studies as support, we hypothesise:

$\mathbf{H}_{5 \mathbf{b}}$ : Greater project formalisation will lead to greater bidirectional communication between the R\&D manager and the marketing manager 


\section{Effects of centralisation}

The effects of centralisation on communication have been examined in several literatures. Hage et al's (1971) study of strategic decision making for example found that decentralisation increased the frequency of unscheduled cross-functional interaction. Conversely, high levels of centralisation on projects can inhibit functional specialists from communicating directly (Olson et al., 1995), and negatively affect information sharing and cross-functional communication during NPD (e.g., Ayers et al., 1997; Gupta and Wilemon, 1988). On this basis we expect higher centralisation to be associated with lower communication frequency, and hypothesise:

$\mathbf{H}_{\mathbf{6 a}}$ : Greater project centralisation will lead to lower communication frequency between the R\&D manager and the marketing manager.

Moenaert et al's (1994) study of integration mechanisms and communication flows between marketing and R\&D during NPD found that project centralisation is negatively associated with communication flows i.e., lower bidirectionality. Similarly, Song et al. (1996) found that higher centralisation during NPD projects had a negative effect on level of information exchange between these functions in the planning phase of the project. We therefore hypothesise:

$\mathbf{H}_{6 \mathrm{~b}}$ : Greater project centralisation will lead to lower bidirectional communication between the R\&D manager and the marketing manager

\section{Method}

\section{Data collection}

Data was collected from R\&D managers in Australian firms, acting as key informants on their working relationship with the marketing manager during a recent NPD project. The survey used a pretested, mailed, self-administered questionnaire. The criteria used to qualify respondents were: (1) the respondent's firm needed to conduct NPD, (2) the firm needed an identifiable manager responsible for $R \& D$, and also an identifiable marketing manager or senior marketing executive.

The sampling frame was generated from a commercial mailing list and screened to eliminate firms unlikely to be involved in NPD. The remaining firms were contacted by telephone, and those not involved in NPD were removed from the sampling frame. In total, 334 managers agreed to participate, and after two waves of follow up telephone calls we received 184 usable responses, a net response rate of 54\%.

\section{Sample characteristics}

The sample of 184 firms comprised mostly goods producers (96.2\%), while the remainder (3.8\%) were software producers. Consumer marketers accounted for 47.0\%, business-to-business marketers $23.5 \%$, and $29.5 \%$ sold into both markets. Tests of nonresponse bias revealed that there were no statistically significant differences between the early and late respondents.

\section{Operational measures}

Two types of measures were used, formative multi-item, and reflective multi-item scales. Our single formative measure is communication frequency, which was assessed using ten items drawn from Fisher et al. (1997). Because peer managers can 
communicate in many ways, e.g., face-to-face, by telephone, by e-mail, we treated communication frequency as an index measure, by asking respondents how frequently they and the marketing manager communicated via each of those methods.

Our seven reflective multi-item measures were: formalisation, centralisation, bidirectional communication, quality of communication, cognition-based trust, affectbased trust, and perceived relationship effectiveness. In selecting our measures of these constructs, we preferred those that were reflective in nature, because this would allow us to test them for dimensionality, reliability, and validity. In addition, we preferred measures which had themselves been tested and validated. Details for each scale can be found in the Appendix.

\section{Measure refinement}

The reflective multi-item measures were tested using exploratory factor analysis and found to be unidimensional. In addition, we carefully examined the wording of our items, and on face validity grounds decided to drop items 2 and 4 from the bank of five items measuring our dependent variable (See Appendix for details).

Following this, we used partial least squares to assess the measurement properties of the remaining items. Our first run of the model was conducted using all of the remaining items, and we examined the "outer" (measurement) model loadings. One item was deleted because of a low standardised loading, suggesting that it did not strongly reflect the associated latent variable (item 4 for bidirectional communication — see Appendix for details).

Convergent validity was established in two ways, first the t-statistics for each indicator were all statistically significant (Anderson and Gerbing, 1988), and second, the average variance extracted (AVE) for each construct exceeded .50 (Fornell and Larcker, 1981). Discriminant validity was also established in two ways. First the squared correlation for all pairs of constructs was less than the AVE for each individual construct (Fornell and Larcker, 1981). Second, we examined the pattern of loadings and cross-loadings of all items on all latent variables in our model. The criterion to establish discriminant validity is that no item should load more heavily on another construct than it does on the construct it is intended to measure (cf. Chin, 1998). All items passed this test, so discriminant validity was established between the constructs in our model. Reliability analysis reveals alpha coefficients for our measures of .79 or higher, and the composite reliabilities all exceeded .88 (see Table I), suggesting good internal consistency in our measures. Overall, the measurement properties of our scales are satisfactory, and suggest that it is appropriate to estimate and evaluate our structural model.

\section{Results}

\section{Descriptive results}

As can be seen from Table I, the mean score for perceived relationship effectiveness is 5.18 (s.d. = 1.36). Because the maximum score for this construct is 7, it seems that on average, relationship effectiveness between the marketing managers and R\&D managers is fairly high. The relatively high standard deviation suggests however, that there is considerable variation in the quality of the relationships in this study.

[Take in Table I] 
Our findings suggest that on average, there is a reasonable amount of interpersonal trust between these managers, cognition-based trust $\bar{X}=5.19$ (s.d. $=1.22$ ), and affectbased trust $\bar{X}=4.83$ (s.d. $=1.54$ ). Also, there is a fairly high level of collaborative communication because bidirectional communication is quite high, $\bar{X}=5.12$ (s.d. $=$ 1.26). Communication quality however, is slightly lower, $\bar{X}=4.65$ (s.d. $=1.37$ ), whilst communication frequency is quite low, $\bar{X}=2.51$ (s.d. $=0.66$ ). Last, the projects in our sample had only moderate levels of formalisation, $\bar{X}=4.02$ (s.d. $=$ 1.55), and low levels of centralisation $\bar{X}=2.69$ (s.d. $=1.37$ ).

\section{Model estimation and testing results}

PLS Graph Version 3 (Chin, 2003) was used to estimate our structural model for a number of reasons. First, our sample size is relatively small $(n=184)$, second, we make no assumptions about the normality of our variables, third, our model includes both formative and reflective measures, and last, our primary aim is to predict endogenous variables such as interpersonal trust (cf. Chin, 1998; Diamantopolous and Winklhofer, 2001).

Our parameter estimates and t-statistics were computed using 500 bootstrap samples. As shown in Table II, thirteen of the sixteen hypotheses were supported. The $\mathrm{R}^{2}$ for perceived relationship effectiveness is .728, suggesting that our model explains $72.8 \%$ of the variance in this endogenous variable. Similarly, $\mathrm{R}^{2}$ for cognition-based trust $=$ .497 , affect-based trust $=.553$, communication quality $=.579$, bidirectional communication $=.221$, and communication frequency $=.132$. Overall, these findings suggest that the dependent variable, and the focal variables of this study (cognitionand affect-based trust) are predicted well in our model.

\section{[Take in Figure 2]}

The results of the hypotheses testing are presented in Figure 2 and Table II, and only three of the sixteen hypotheses were non significant. Six of the our seven hypotheses relating to interpersonal trust were supported, consistent with our arguments that interpersonal trust is one of the most important factors influencing marketing/R\&D relationships during NPD projects. Specifically, both forms of trust greatly increase the effectiveness of the marketing/R\&D relationship. Cognition-based trust $\rightarrow$ perceived relationship effectiveness $(\beta=.399, \mathrm{p}<.001)$, and affect-based trust $\rightarrow$ perceived relationship effectiveness $(\beta=.252, \mathrm{p}<.001)$. In addition, our results suggest that cognition-based trust has a strong positive effect on affect-based trust ( $\beta$ $=.511, \mathrm{p}<.001)$.

Turning now to the effects of communication behaviours on interpersonal trust, three of our four hypotheses were supported. The strongest effect observed was communication quality $\rightarrow$ cognition-based trust $(\beta=.529, \mathrm{p}<.001)$, followed by bidirectional communication $\rightarrow$ affect-based trust $(\beta=.311, \mathrm{p}<.001)$, and bidirectional communication $\rightarrow$ cognition-based trust $(\beta=.189, \mathrm{p}<.05)$. However, no relationship was found between communication frequency and cognition-based trust $(\beta=.052, \mathrm{p}>.05)$.

Our results also reveal that bidirectional communication strongly affects the quality of communication exchanged between the two managers $(\beta=.761, p<.001)$, and that communication frequency can increase bidirectional communication in this relationship ( $\beta=.362, \mathrm{p}<.001$ ). This suggests that various communication behaviours work in combination within NPD teams, often reinforcing each other. 
Interestingly, the direct effects of the communication behaviours on perceived relationship effectiveness were relatively modest, as communication frequency had a small but statistically significant influence on relationship effectiveness ( $\beta=.096$, $p$ $<.05)$, as did communication quality, though the effect was somewhat stronger $(\beta=$ $.175, \mathrm{p}<.05)$. Bidirectional communication however, had no significant influence on perceived relationship effectiveness $(\beta=.099, \mathrm{p}>.05)$.

Our results regarding Weber's (1924) bureaucratic dimensions were mostly supported. Formalisation had a positive effect on both communication frequency ( $\beta=$ .337, $\mathrm{p}<.001)$, and on bidirectional communication $(\beta=.138, \mathrm{p}<.05)$. Last, centralisation had the expected negative effect on bidirectional communication ( $\beta=$ $.142, \mathrm{p}<.05)$, but none on communication frequency $(\beta=-.119, \mathrm{p}>.05)$, though the sign was in the hypothesised direction.

[Take in Table II]

\section{Discussion}

\section{Theoretical implications}

In our conceptual model we integrate Weberian, and interaction-based theories to examine the effects of structural, and individual-level variables in marketing/R\&D relationships during NPD projects. As predicted, both of the focal constructs of this research, cognition- and affect-based trust, have a strong positive impact on our dependent variable - perceived relationship effectiveness, with cognition-based trust having the stronger effect.

R\&D managers with cognition- and affect-based trust in their counterpart marketing manager are therefore more likely to perceive that their relationship is effective. Our findings therefore support the view that trust can help break down the barriers between the "functional silos" represented by separate departments (Dougherty, 1992), which reduce the ability of managers from different functional units to work together effectively. This is important because departments with conceptual and operational domains as dissimilar as marketing and R\&D have a high potential to develop ineffective working relationships, and our findings corroborate theory suggesting that interpersonal trust is a key factor allowing these two functions to work together more effectively. Recall that cognition-based trust concerns work related competence and reliability, and by extension, task accomplishment. Our results show clearly that the task related outcomes on NPD projects are likely to be substantial when cognition-based trust is present, as no other construct has a greater influence on the effectiveness of the marketing/R\&D relationship during NPD. Affect-based trust also has strong effects on our dependent variable, but these are not as powerful as the effects of cognition-based trust.

Our results also corroborate McAllister (1995), who found that cognition-based trust was a strong predictor of affect-based trust in peer manager relationships, and that some level of cognition-based trust might be necessary before affect-based trust emerges. This is important because whilst our results suggest that affect-based trust has only approximately $60 \%$ of the impact of cognition-based trust on the effectiveness of marketing/R\&D relationships, where it is present it can further increase the likelihood of NPD teams developing successful new products.

Our findings also provide insights into the role of various communication behaviours in marketing/R\&D relationships. Specifically, while two of the three 
communication dimensions in our model directly influence relationship effectiveness, their strongest effects are indirect. An important finding of our research is that both bidirectional communication and communication quality have strong trust-building effects. Where marketing managers provide high quality information to the R\&D manager, this greatly increases the perceived competence of the marketing manager, and cognition-based trust is likely to develop. Similarly, bidirectionality helps increase both forms of interpersonal trust. This is most likely because bidirectional communication is a reciprocal form of communication which can help demonstrate not only the work related competence required for cognition-based trust to emerge, but also the good personal intentions of the other manager required for affect-based trust to emerge. An important theoretical implication of our findings is that the functional effects of communication in improving relationship effectiveness appear to be mostly indirect, operating through various mediating variables such as interpersonal trust.

A further theoretical implication is that contrary to the interactionist viewpoint, frequent communication does not greatly improve effectiveness directly. Its strongest effects are in stimulating bidirectional communication. This may be due to the norms of reciprocity in social systems discussed by Gouldner (1960), in which unidirectional communication between peer managers is likely to elicit a response, and thereby increase bidirectional communication. This finding is important because as noted above, bidirectional communication is associated with the development of both forms of trust, which in turn, are strong predictors of relationship effectiveness.

Turning now to the impact of Weber's (1924) structural/bureaucratic variables, our results suggest that formalisation is useful during NPD because it greatly increases communication frequency, and also increases bidirectional communication between marketing managers and R\&D managers. Our results therefore reveal two important things: first, that formalisation is effective as a coordination mechanism during NPD. Second, we present evidence regarding how formalisation works during NPD, i.e., in stimulating effective exchanges between members of the NPD project team.

Further, our results reveal that as expected, centralisation decreases bidirectional communication, and though the path coefficient linking centralisation to communication frequency was not statistically significant, it was in the hypothesised negative direction. Our results are therefore somewhat inconsistent with arguments that creative activities such as NPD benefit from more "organic" structures, with lower levels of formalisation and centralisation. It appears that whilst centralisation does decrease bidirectional communication as expected, some minimum level of bureaucratic "initiation of structure" (e.g., Stogdill, 1974) such as formalisation, is necessary on NPD projects.

\section{Managerial Implications}

Our findings have implications for firms using cross-functional teams including marketing and R\&D to develop new products, and our model testing provides insights into how to improve marketing/R\&D relationships during such projects. One encouraging finding is that contrary to some previous studies (e.g., Souder, 1981, 1988; Shaw and Shaw, 1998), in many firms this relationship is healthy. This is important because successful NPD requires marketing managers and R\&D managers to work together effectively (Gupta et al., 1986; Olsen et al., 1995).

The key managerial implication of our research however, is the salience of interpersonal trust during NPD projects. Marketing managers should be aware that in 
order for R\&D managers to begin trusting them, they must first demonstrate their competence and professionalism. Once this competence is demonstrated, cognitionbased trust may develop, and the qualitatively more "special" form of trust, affectbased trust may then emerge (Johnson-George and Swap, 1982). The positive effects of these two forms of trust on relationship effectiveness, both singly, and in combination, is substantial.

A second set of implications relates to the importance of effective communication during NPD projects. In particular, both the quality and bidirectionality of communication are important because they are potent factors building interpersonal trust between marketing managers and $R \& D$ managers. This finding is significant because the more effective the marketing/R\&D relationship, the greater the likelihood of new product success (Ruekert and Walker, 1987; Song et al., 2000). Hence the flow-on effects of effective communication, and interpersonal trust can ultimately influence "hard" measures of firm performance such as profitability, by improving new product success rates.

A final implication of this research is that bureaucratic methods of crossfunctional coordination such as formalisation, can provide a useful payoff by helping increase both the frequency and bidirectionality of communication flows between marketing managers and R\&D managers. This in turn can help build trust, and effectiveness in the marketing/R\&D relationship during NPD. In addition, and consistent with Weber's (1924) theory of bureaucracy, more decentralised structures seem more appropriate for complex tasks such as NPD, because too much centralisation seems to inhibit the exchange of information between new product team members.

\section{Limitations and directions for future research}

A major limitation of our research is that it is restricted to R\&D managers' perceptions of the relationship. Future research should use dyadic data to examine the relationship from the perspective of both $R \& D$ managers and marketing managers.

Another limitation concerns our subjective outcome measure - perceived relationship effectiveness. Whilst other studies have used this same approach (e.g., Anderson and Narus, 1990; Smith and Barclay, 1997), and given sound justification for doing so, given the context of our research, future work could use an objective, hard measure such as new product success as the dependent variable.

We also recognise that one of the assumptions underlying our model testing procedure is the linearity of the structural relations between the model constructs. It is possible that some of these relations are non-linear, and further research could explicitly test the linearity of these relationships.

Another suggestion concerns our choice of theoretical frameworks - the interaction approach, and Weber's (1924) theory of bureaucracy. Cross-functional relationships are affected by a wide range of factors, and while these theoretical frameworks have provided important insights, future research could draw on other frameworks such as structural contingency theory (e.g., Donaldson, 1996), or resource dependence theory (e.g., Pfeffer and Salancik, 1978). This would open up different sets of explanatory variables, e.g., the impact of various "lateral linkage devices" (Olson et al., 1995), on trust and relationship effectiveness. In addition, it would be useful to examine the impact of other individual-level variables identified in the literature, e.g., interpersonal conflict, as conflict is an important behavioural variable with potent effects on cross-functional relationships, and a wide range of other social and exchange relationships. 


\section{References}

Aiken, M. and Hage. J. (1968), "Organisational interdependence and intraorganisational structure”, American Sociological Review, Vol. 33, pp. 912-30.

Anderson, J.C. and Gerbing, D.A. (1988), "Structural equation modeling in practice: a review and recommended two-step approach”, Psychological Bulletin, Vol. 103 No. 3, pp. 411-23.

Anderson, J.C. and Narus, J.A. (1990), “A model of distributor firm and manufacturer firm working partnerships”, Journal of Marketing, Vol. 54, January, pp. 42-58.

Anderson, E. and Weitz, B. (1989), "Determinants of continuity in conventional industrial channel dyads”, Marketing Science, Vol. 8, pp. 310-23.

Ashforth, B.E. and Lee, R.T. (1990), "Defensive behavior in organizations: a preliminary model”, Human Relations, Vol. 43, pp. 621-48.

Ayers, D., Dahlstrom, R. and Skinner, S.J. (1997), "An exploratory investigation of organizational antecedents to new product success", Journal of Marketing Research, Vol. 34, February, pp. 107-16.

Bagozzi, R.P. and Yi, Y. (1988), “On the evaluation of structural equation models”, Journal of the Academy of Marketing Science, Vol. 16 No. 1, pp. 74-94.

Becerra, M. and Gupta, A.K. (2003), "Perceived trustworthiness within the organization: the moderating impact of communication frequency on trustor and trustee effects”, Organization Science, Vol. 14 No. 1, January-February, pp. 32-44.

Björk, L.E. (1975), “An experiment in work satisfaction”, Scientific American, March, pp. 17-23.

Blau, P.M. (1964), Exchange and Power in Social Life, John Wiley and Sons, New York.

Boyle, R. and Bonacich, P. (1970), “The development of trust and mistrust in mixedmotive games”, Sociometry, Vol. 33 No. 2, pp. 123-139.

Burns, T. and Stalker, G.M. (1961), The Management of Innovation, Tavistock, London.

Chin, W.W. (1998), "The partial least square approach to structural equation modeling”, in Marcoulides, G.A. (Ed.), Modern Methods for Business Research, Lawrence Erlbaum Associates Publishers, Mahwah, NJ, pp. 295336.

Chin, W.W. (2003), PLS Graph Version 3, Soft Modeling Inc.

Clark, M.M., Mills, J. and Corcoran, D.M. (1989), "Keeping track of needs and inputs of friends and strangers", Personality and Social Psychology Bulletin, Vol. 15, pp. 533-42.

Cooper, R.G. (1996), “Overhauling the new product process”, Industrial Marketing Management, Vol. 25, pp. 465-82.

Crawford, C.M. and DiBenedetto, A. (2003), New Products Management, $7^{\text {th }}$ Ed, McGraw-Hill Irwin, New York.

Dasgupta, P. (1988) “Trust as a commodity”, in Gambetta, D.G. (Ed.), Trust: Making and Breaking Cooperative Relations, Basil Blackwell, New York, pp. 49-72.

Dawes, P.L. and Massey, G.R. (2005), “Antecedents of conflict in marketing's crossfunctional relationship with sales”, European Journal of Marketing, Vol. 39 No. 11/12, pp. 1327-44. 
Dawes, P.L. and Massey, G.R. (2006), “A study of relationship effectiveness between marketing and sales managers in business markets", Journal of Business and Industrial Marketing, Vol. 21 No. 6, pp. 346-360.

Diamantopoulos, A. and Winklhofer, H.M. (2001), "Index construction with formative indicators: an alternative to scale development", Journal of Marketing Research, Vol. 38, May, pp. 269-77.

Donaldson, L. (1996), “The normal science of structural contingency theory", in Clegg, S.R., Hardy, C. and Nord, W.R. (Eds), Handbook of Organization Studies, Sage, London, pp. 57-76.

Doney, P.M. and Cannon, J.P. (1997), "An examination of the nature of trust in buyer-seller relationships”, Journal of Marketing, Vol. 61, April, pp. 35-51.

Dougherty, D. (1992), "Interpretive barriers to successful product innovation in large firms”, Organization Science, Vol. 3 No. 2, pp. 179-202.

Fisher, A.B. (1978), Perspectives on human communication, MacMillan Publishing, New York.

Fisher, R.J., Maltz, E. and Jaworski, B.J. (1997), "Enhancing communication between marketing and engineering: the moderating role of relative functional identification”, Journal of Marketing, Vol. 61, July, pp. 54-70.

Fornell, C. and Larcker, D.F. (1981), "Evaluating structural equation models with unobservable variables and measurement error”, Journal of Marketing Research, Vol. 18, February, pp. 39-50.

Gabarro, J. (1990), “The development of working relationships”, in Galagher, J., Kraut, R.E., and Egido, C. (Eds), Intellectual Teamwork: Social and Technological Foundations of Cooperative Work, Erlbaum, Hillsdale, NJ, pp. 79-110.

Ganesan, S. (1994), "Determinants of long-term orientation in buyer-seller relationships”, Journal of Marketing, Vol. 58, April, pp. 1-19.

Ganesan, S. and Hess, R. (1997), "Dimensions and levels of trust: implications for commitment to a relationship”, Marketing Letters, Vol. 8, October, pp. 43948.

Good, D. (1988), “Individuals, interpersonal relations, and trust”, in Gambetta, D. (Ed), Trust: Making and Breaking Cooperative Relations, Basil Blackwell, New York, pp. 31-48.

Gouldner, A.W. (1960), "The norm of reciprocity: a preliminary statement", American Sociological Review, Vol. 25 No. 2, pp. 161-78.

Griffin, A. and Hauser, J.R. (1996), "Integrating R\&D and marketing: a review and analysis of the literature”, Journal of Product Innovation Management, Vol. 13, pp. 191- 215.

Gupta, A.K., Raj, S.P. and Wilemon, D. (1985), “The R\&D/marketing interface in high-technology firms”, Journal of Product Innovation Management, Vol. 2, pp. 12-24.

Gupta, A.K., Raj, S.P. and Wilemon, D. (1986), "A model for studying the R\&Dmarketing interface in the product innovation process”, Journal of Marketing, Vol. 50 No. 2, April, pp. 7-17.

Gupta, A.K. and Wilemon, D. (1988), "The credibility-cooperation connection at the R\&D-marketing interface”, Journal of Product Innovation Management, Vol. 5, pp. 20-31.

Gupta, A.K. and Wilemon, D. (1990), “Improving R\&D/marketing relations: R\&D’s perspective”, R\&D Management, Vol. 20 No. 4, pp. 277-90. 
Hage, J., Aiken, M. and Marrett, C.B. (1971), "Organization structure and communications”, American Sociological Review, Vol. 3, pp. 860-71.

Huber, G.P. and Daft, R.L. (1987), “The information environment of organizations”, in Jablin, F.M., Putnam, L.L., Roberts, K. and Porter, LW. (Eds), Handbook of Organizational Communication: An Interdisciplinary Perspective, Sage Publications Inc., Newbury Park, CA, pp. 130-64.

Jassawalla, A.R. and Sashittal, H.C. (1998), "An examination of collaboration in hightechnology new product development processes”, Journal of Product Innovation Management, Vol. 15, pp. 237-54.

Johnson-George, C.E. and Swap, W.C. (1982), "Measurement of specific interpersonal trust: construction and validation of a scale to assess trust in a specific other", Journal of Personality and Social Psychology, Vol. 43, pp. 1306-17.

Jones, G.R. and George, J.M. (1998), "The experience and evolution of trust: implications for cooperation and teamwork", Academy of Management Review, Vol. 23 No. 3, pp. 531-546.

Jones, C., Hesterly, W.S. and Borgatti, S.P. (1997), "A general theory of network governance: exchange conditions and social mechanisms”, Academy of Management Review, Vol. 22 No. 4, pp. 911-45.

Lawrence, P.R. and Lorsch, J.W. (1967), Organization and Environment, IrwinDorsey, Homewood, ILL.

Lewis, J.D. and Weigert, A. (1985), “Trust as a social reality”, Social Forces, Vol. 63, pp. 967-85.

Maltz, E., Souder, W.E. and Kumar, A. (2001), "Influencing R\&D/marketing integration and the use of market information by R\&D managers: intended and unintended effects of managerial actions”, Journal of Business Research, Vol. 52, pp. $69-82$.

McAllister, D.J. (1995), “Affect- and Cognition-Based Trust as Foundations for Interpersonal Cooperation in Organizations," Academy of Management Journal, Vol. 38 No. 1, pp. 24-59.

McCann, J. and Galbraith, J.R. (1981), "Interdepartmental relations", in Nystrom, P.C. and Starbuck, W.H. (Eds), Handbook of Organizational Design, Volume 2. Remodelling Organisations and their Environment, Oxford University Press, pp. 60-84

Mintzberg, H. (1979), The Structuring of Organizations, Prentice-Hall, Englewood Cliffs, NJ.

Mittal, B. (1996), “Trust and relationship quality: a conceptual excursion”, Centre for Relationship Marketing Conference Proceedings, June, pp. 230-40.

Moenaert, R.K. and Souder, W.E. (1990a), “An information transfer model for integrating marketing and $\mathrm{R} \& \mathrm{D}$ personnel in new product development projects”, Journal of Product Innovation Management, Vol. 7, June, pp. 91107.

Moenaert, R.K. and Souder, W.E. (1990b), “An analysis of the use of extrafunctional information by R\&D and marketing personnel: review and model”, Journal of Product Innovation Management, Vol. 7, June, pp. 213-29.

Moenaert, R.K., Deschoolmeester, D., De Meyer, A. and Souder, W.E. (1992), "Information styles of marketing and R\&D personnel during technological product innovation projects”, $R \& D$ Management, Vol. 22 No. 1, pp. 21-39.

Moenaert, R.K., Souder, W.E., DeMeyer, A., and Deschoolmeester, D. (1994), "R\&Dmarketing integration mechanisms, communication flows, and innovation 
success”, Journal of Product Innovation Management, Vol. 11, January, pp. 3145.

Mohr, J.J., Fisher, R.J. and Nevin, J.R. (1996), "Collaborative communication in interfirm relationships: moderating effects of integration and control”, Journal of Marketing, Vol. 60, July, pp. 103-15.

Morgan, R.M. and Hunt, S.D. (1994), "The commitment-trust theory of relationship marketing”, Journal of Marketing, Vol. 58, July, pp. 20-38.

Morgan, N.A. and Piercy, N.F. (1998), "Interactions between Marketing and Quality at the SBU Level: Influences and Outcomes", Journal of the Academy of Marketing Science, Vol. 26 No. 3, pp. 190-208.

Olson, E.M., Walker, O.C. Jnr. and Ruekert, R.W. (1995), "Organizing for effective new product development: the moderating role of product innovativeness", Journal of Marketing, Vol. 59, January, pp. 48-62.

Pennings, J.M. (1992), "Structural contingency theory: a reappraisal”, in Staw, B.M. and Cummings, I.I. (Eds), Research in Organizational Behavior, pp. 267-309.

Pennings, J.M. and Woiceshyn, J. (1987), "A typology of organizational control and its metaphors”, in Bacharach, S.B. and Mitchell, S.M. (Eds), Research in the Sociology of Organizations, Vol. 5, JAI Press, Greenwich, CT, pp. 75-104.

Pfeffer, J. and Salancik, G.R. (1978). The External Control of Organizations: A Resource Dependence Perspective, Harper and Row, New York.

Pugh, D., Hickson, D., Hinings, C.R. and Turner, C. (1968), "Dimensions of organizational structure”, Administrative Science Quarterly, Vol. 13, June, pp. 65-105.

Rajagopalan, N., Rasheed, A.M.A. and Datta, D.K. (1993), "Strategic decision processes: critical review and future directions”, Journal of Management, Vol. 19, Summer, pp. 349-84.

Rempel, J.K., Holmes, J.G. and Zanna, M.D. (1985), “Trust in close relationships”, Journal of Personality and Social Psychology, Vol. 49, pp. 95-112.

Rousseau, D.M., Sitkin, S.B., Burt, R.S. and Camerer, C. (1998), "Not so different after all: a cross-discipline view of trust”, Academy of Management Review, Vol. 23 No. 3, pp. 393-404.

Ruekert, R.W. and Walker, O.C. (1987), "Marketing's interaction with other functional units: a conceptual framework and empirical evidence”, Journal of Marketing, Vol. 51, January, pp. 1-19.

Seabright, M.A., Leventhal, D.A. and Fichman, M. (1992), "Role of individual attachments in the dissolution of interorganizational relationships”, Academy of Management Journal, Vol. 35, pp. 122-60.

Shaw, V. and Shaw, C.T. (1998), "Conflict between engineers and marketers", Industrial Marketing Management, Vol. 27, pp. 279-91.

Sheppard, B.H. and Sherman, D.M. (1998), "The grammars of trust: a model and general implications”, Academy of Management Review, Vol 23 No.3, pp. 422-437.

Smith, B.J. and Barclay, D.W. (1997), "The effects of organizational differences and trust on the effectiveness of selling partner relationships", Journal of Marketing, Vol. 61, January, pp. 3-21.

Solomon, L. (1960) "The influence of some types of power relationships and game strategies upon the development of interpersonal trust”, Journal of Abnormal and Social Psychology, Vol. 61, pp. 223-230. 
Song, X.M., Neeley, S.M. and Zhao, Y. (1996), "Managing R\&D-marketing integration in the new product development process", Industrial Marketing Management, Vol. 25, pp. 545-53.

Song, X.M., Xie, J. and Dyer, B. (2000), “Antecedents and consequences of marketing managers' conflict handling behaviours”, Journal of Marketing, Vol. 64, January, pp. 50-66.

Souder, W.E. (1981), "Disharmony between R\&D and marketing", Industrial Marketing Management, Vol. 10, pp. 67-73.

Souder, W.E. (1987), Managing New Product Innovations, Lexington Books, Lexington, Mass.

Souder, W.E. (1988), "Managing relations between R\&D and marketing in the new product development process", Journal of Product Innovation Management, Vol. 5, March, pp. 6-19.

Souder, W.E., and Moenaert, R.K. (1992), "Integrating marketing and R\&D personnel within innovation projects: an information uncertainty model”, Journal of Management Studies, Vol. 29 No. 4, pp. 485 - 512.

Stogdill, R.M. (1974), Handbook of Leadership: A Survey of Theory and Research, Free Press, New York.

Thompson, J.D. (1967), Organizations in Action, McGraw-Hill, New York.

Van de Ven, A. (1976), "On the nature, formation, and maintenance of relations among organizations”, Academy of Management Review, Vol. 4, October, pp. 24-36.

Van de Ven, A.H. and Ferry, D.L. (1980), Measuring and Assessing Organizations, John Wiley and Sons, New York.

Weber, M. (1924), The Theory of Social and Economic Organisation, (Trans.) Henderson, A.H. and Parsons, T. (1947), The Free Press, New York. (First published in German in 1924).

Webster, F.E. Jnr. (1997), "The future role of marketing in the organization", in Lehmann, D.R. and Jocz, K.E. (Eds), Reflections on the Futures of Marketing, Marketing Science Institute, Cambridge, MA.

Wheelwright, S.C. and Clark, K.B. (1992), Revolutionizing Product Development, The Free Press, New York.

Williams, M. (2001), "In whom we trust: group membership as an affective context for trust development”, Academy of Management Review, Vol. 26 No. 3, pp. 377-96.

Wind, Y.J. (1981), "Marketing and Other Business Functions", in Research in Marketing, Sheth, J. (Ed.), JAI Press, Greenwich, CONN., pp. 237-264.

Wind, Y.J. (1982), Product Policy: Concepts, Methods and Strategy, Addison-Wesley Publishing Co., Reading, MASS.

Workman, J.P. Jr., Homburg, C. and Gruner, K. (1998), "Marketing organization: an integrative framework of dimensions and determinants", Journal of Marketing, Vol. 62, July, pp. 21-41.

Young, L.C. and Wilkinson, I.F. (1997), "The space between: towards a typology of interfirm relations”, Journal of Business to Business Marketing, Vol. 4 No. 2, pp. 53-97. 